\title{
МОДУЛЯЦИОННАЯ НЕУСТОЙЧИВОСТЬ ПОПЕРЕЧНО ОГРАНИЧЕННЫХ ЭЛЕКТРОМАГНИТНЫХ ВОЛН ТЕРАГЕРЦОВОГО ДИАПАЗОНА В ПАРАЭЛЕКТРИКЕ ТИТАНАТ СТРОНЦИЯ*
}

\author{
КОШЕВАЯ С. В., ГРИМАЛЬСКИЙ В. В., КОЦАРЕНКО Ю. Н., ТЕКПОЙОТЛЬ-ТОРРЕС М.
}

\author{
Автономный университет штата Морелос, \\ Мексика, Куэрнавака, Z. Р. 62209
}

\begin{abstract}
Аннотация. В рамках построенной приближенной феноменологической модели теоретически исследована модуляционная неустойчивость поперечно ограниченных электромагнитных волн терагерцового диапазона в параэлектрических кристаллах $\mathrm{SrTiO}_{3}$ при температурах порядка 77 К. Кубичная нелинейность и частотная дисперсия соответствуют существованию модуляционной неустойчивости протяженных входных импульсов. Приведены результаты численных исследований модуляционной неустойчивости. Поперечная ограниченность входных импульсов может стабилизировать модуляционную неустойчивость. Порог модуляционной неустойчивости понижается при наличии отражений от границ кристалла. При развитии модуляционной неустойчивости имеется возможность генерации последовательности коротких терагерцовых импульсов на выходе кристалла. Фокусировка входных импульсов понижает порог модуляционной неустойчивости.
\end{abstract}

Ключевые слова: ТГц излучение; кубичная нелинейность; частотная дисперсия; модуляционная неустойчивость; короткие импульсы

\section{1. ВВЕДЕНИЕ}

В последнее время активно осваивается терагерцовый (ТГц) диапазон 0,1-30 ТГц, который имеет приложения в интроскопии, спектроскопии, широкополосной связи, радиоастрономии и радиовидении [1-3]. Для генерации коротких ТГц импульсов используются лазеры и оптоэлектронные антенны [1-5]. Также короткие импульсы могут быть получены при модуляционной неустойчивости (МH) длинных входных импульсов [6].

Для МН требуется наличие кубичной нелинейности и частотной дисперсии определен- ных знаков. МН - это неустойчивость нелинейной волны с постоянной амплитудой, которая проявляется в осцилляциях амплитуды волны во времени и в пространстве, при условии, если входная амплитуда выше определенной пороговой [6].

В качестве нелинейных сред в СВЧ диапазоне используются нелинейные диэлектрики, в особенности сегнетоэлектрики в неполярной фазе, так называемые параэлектрики титанат стронция $\mathrm{SrTiO}_{3}$, танталат калия $\mathrm{KTaO}_{3}$, и керамики на их основе [7-16]. Параэлектрики имеют высокую электродинамическую нелинейность и малые потери при низких темпера-

* Работа частично поддержана SEP-CONACyT, Mexico. 


\section{БИБЛИОГРАФИЧЕСКИЙ СПИСОК}

1. Lee Y.-S. Principles of Terahertz Science and Technology / Yun-Shik Lee. — N.Y. : Springer, 2009. 340 p. - DOI : 10.1007/978-0-387-09540-0.

2. Perenzoni $M$. Physics and Applications of Terahertz Radiation / Matteo Perenzoni, Douglas J. Paul (eds.). - N.Y. : Springer, 2014. - 255 p. - DOI : 10.1007/978-94-007-3837-9.

3. Siegel P. H. Terahertz pioneer: Erik L. Kollberg "Instrument Maker to the Stars" / Peter H. Siegel // IEEE Trans. Terahertz Sci. Technology. - Sept. 2014. - Vol. 4, No. 5. - P. 538-544. - DOI : 10.1109/TTHZ.2014. 2344191.

4. Tunable broadband frequency-multiplied terahertz sources / John S. Ward, Goutam Chattopadhyay, John Gill, Hamid Javadi, Choonsup Lee, Robert Lin, Alain Maestrini, Frank Maiwald, Imran Mehdi, Erich Schlecht, Peter Siegel // Infrared, Millimeter and Terahertz Waves : 33rd Int. Conf. IRMMW-THz, 15-19 Sept. 2008, Pasadena, CA : proc. — IEEE, 2008. - P. 1-3. — DOI : $10.1109 /$ ICIMW.2008.4665437.

5. Лебедев А.И. Физика полупроводниковых приборов / А. И. Лебедев. - М. : Физматлит, 2008. $488 \mathrm{c}$.

6. Кившарь Ю. С. Оптические солитоны. От волоконных световодов к фотонным кристаллам / Ю. С. Кившарь, Г. П. Агравал. - М. : Физматлит, 2006. $648 \mathrm{c}$.

7. Вендик О. Г. Сегнетоэлектрики в технике СВЧ/ О. Г. Вендик. - М. : Сов. Радио, 1979. - 272 с. 
8. Рез И. С. Диэлектрики. Основные свойства и применения в электронике / И. С. Рез, Ю. М. Поплавко. - М. : Радио и связь, 1989. - 288 с.

9. Фізичне матеріалознавство. Т. 2: Діелектрики / Ю. М. Поплавко, Л. П. Переверз, С. О. Воронов, Ю. І. Якименко. - К. : КПІ, 2007. - 391 с.

10. Gevorgian S. Ferroelectrics in Microwave Devices, Circuits and Systems / Spartak Gevorgian. N.Y. : Springer, 2009. - 394 p. - DOI : 10.1007/978-184882-507-9.

11. Низкотемпературные сегнетоэлектрики: Диэлектрическая проницаемость, потери и параметрические взаимодействия на СВЧ / И. М. Бузин, И. В. Иванов, Г. В. Белокопытов, В. М. Сычев, В. Ф. Чупраков // Физика. - 1981. — Т. 24, № 8. - С. 6-28. - (Известия вузов).

12. Параметрическое и нелинейное взаимодействие электромагнитных волн в параэлектриках / Л. Г. Гассанов, С. В. Кошевая, Т. Н. Нарытник, М. Ю. Омельяненко // Радиоэлектроника. - 1978. - Т. 21, № 10. - С. 56-63. - (Известия вузов).

13. Кошевая C. В. Генерация третьей гармоники в нелинейном диэлектрике без дисперсии / С. В. Кошевая, Л. Г. Гассанов, М. Ю. Омельяненко // Украинский физический журнал. - 1980. - Т. 25, № 7. - С. 1118-1123.

14. Кочевая C. В. Влияние дисперсии в волноведущих системах с кубично нелинейными диэлектриками / С. В. Кошевая, М. В. Кононов, М. Ю. Омельяненко // Радиоэлектроника. - 1985. - Т. 28, № 3. С. 53-56. - (Известия вузов).

15. Кононов М. В. Нелинейные СВЧ волны в кристаллах / М. В. Кононов, С. В. Кошевая, М. Ю. Омельяненко // Квантовая электроника. - 1984. — № 26. С. 55-68. - (Сб. трудов ин-та физики полупроводников АН УССР).

16. Гассанов Л. Г. Об умножении частот в параэлектриках / Л. Г. Гассанов, С. В. Кошевая, М. Ю. Омельяненко // Радиотехника и электроника. - 1980. — T. 25, № 6. - C. 1238-1243.

Поступила в редакцию 19.11.2015
17. Гримальский В. В. Автомодуляционная неустойчивость и солитоны в сегнетоэлектриках / В. В. Гримальский, С. В. Кошевая // Письма в ЖТФ. 1987. — T. 13, № 17. — C. 1070-1073.

18. Vugmeyster I. D. Development of a terahertz time-domain spectrometer optimized at 5-8 THz and the study of surface polaritons in $\mathrm{NiO}-\mathrm{SrTiO}_{3}$ nano-composite ceramics / Ilya D. Vugmeyster // PhD dissertation. The University of Michigan. - 2013. - 121 p. - URL : http://hdl.handle.net/2027.42/99843.

19. The low-temperature infrared optical functions of $\mathrm{SrTiO}_{3}$ determined by reflectance spectroscopy and spectroscopic ellipsometry / K. Kamars, K.-L. Barth, F. Keilmann, R. Henn, M. Reedyk, C. Thomsen, M. Cardona, J. Kircher, P. L. Richards, J.-L. Stehle // J. Appl. Phys. 1995. - Vol. 78, No. 3. - P. 1235-1240. - DOI : $\underline{10.1063 / 1.360364 .}$

20. Tunable ferroelectric ceramic-polymer composites for sub-THz applications / Y. Yashchyshyn, K. Godziszewski, P. Bajurko, J. Modelski, M. Szafran, E. Bobryk, E. Pawlikowska, G. Tarapata, J. Weremczuk, R. Jachowicz // 43rd European Microwave Conf. : EuMC, 7 -10 Oct. 2013, Nuremberg, Germany : proc. - IEEE, 2013. - P. 676-679. — URL : http://ieeexplore.ieee.org/ $\mathrm{xpl} /$ articleDetails.jsp?tp=\&arnumber $=6686746$.

21. Умножение частот терагерцового излучения в кристаллах параэлектрика титаната стронция / А. Замудио-Лара, С. В. Кошевая, В. В. Гримальский, Ф. Яньез-Кортес // Радиоэлектроника. — 2015. — Т. 58, № 9. - С. 33-40. - (Известия вузов). - Режим доступа : http://radio.kpi.ua/article/view/S0021347015090034.

22. Kodama $Y$. Nonlinear pulse propagation in a monomode dielectric guide / Y. Kodama, A. Hasegawa // IEEE J. Quantum Electron. - May 1987. — Vol. 23, No. 5. - P. 510-524. - DOI : 10.1109/JQE.1987.1073392.

23. Марчук Г. И. Методы расщепления / Г. И. Марчук. - М. : Наука, 1988. — 264 с.

24. Самарский A. A. Теория разностных схем / А. А. Самарский. - М. : Наука, 1989. — 616 с.

После переработки 15.06.2016 